\title{
The examination of motivational climate and goal orientation in basketball players-who did and did not experience a sports injury
}

\author{
Ibrahim Bashan ${ }^{1}$ \\ Turhan Toros ${ }^{2}$
}

\begin{abstract}
Aim: In this research it was aimed if there is a difference between mastery-performance climate and task-ego orientation variables of basketball players who did and did not experience a sports injury.

Methods: This study group consists of 165 male basketball players who experienced mid-degree and serious sports injuries that are actively playing basketball in 18 years and older basketball teams and 142 male basketball players who did not experience any sports injury, or experienced a minor injury that are actively playing basketball in 18 years and older basketball teams, in total, 307 male basketball players. Participation to the study was done appropriately to the principles of voluntariness and privacy. As data collecting tools, "Perceived Motivational Climate in Sport Questionnaire" and Task and Ego Orientation in Sport Questionnaire" were used. For data analysis, the Kolmogorov Smirnov test was used to determine if points show normal distribution or not. Also descriptive statistics, Mann Whitney U-test from the nonparametric tests because the distribution was not normal and in order to determine the relation between measure lower dimension Spearman Correlation tests were used. In order to calculate the internal consistency of the scales, Cronbach Alpha test was considered.

Findings: According to the research findings, as a result of Mann Whitney U-test no meaningful difference was found between basketball players's mastery climate average points ( $U=8902$, $\mathrm{p}>0.05)$, performance climate average points $(\mathrm{U}=9121, \mathrm{p}>0.05)$ goal orientation average points $(\mathrm{U}=9432, \mathrm{p}>0.05)$, ego orientation average points who did and did not experience a sports injury. There is positively meaningful relationship between Goal orientation and Mastery climate $(\mathrm{r}=0,341)$, Ego orientation and Performance climate $(\mathrm{r}=0,618)$.

Conclusions: As a result by handling interactions of different dimensions of sports psychology together, it is thought that it is possible to open new horizons in treating or preventing sports injuries in the future.
\end{abstract}

Keywords: Sports injury; motivational climate; basketball player.

\footnotetext{
1 Assist. Prof., MD., Mersin University, Department of Medical Education, Medical Faculty, Mersin, $\underline{\text { bashan }(\text { yahoo.com }}$

2 Assoc. Prof. PhD., Mersin University, School of Physical Education and Sports, Coaching Education Department, Mersin, turhantoros@yahoo.com
} 
Bashan, I., \& Toros, T. (2018). The examination of motivational climate and goal orientation in basketball players-who did and did not experience a sports injury. Journal of Human Sciences, 15(4), 1854-1862. doi:10.14687/jhs.v15i4.5503

\section{Introduction}

One of the important part of life is sport. Despite the Sport standing out with its game like aspect, is termed as all the activities that are connected to specific rules, today it's defined as total activities stand out with their competitive aspect.

While doing sports, lots of wounds and injuries occur. Sports injuries includes situations when endurance limits are exceeded as a result of the body or a part of the body encounters with a force stronger than normal (Timpka et al. 2014). With another definition, sports injuries can be defined as the cases when participation in sports activities is prevented after the day the injury has occurred. With this approach, National Athletic Injury Reporting System (NAIRS) organization has divided sports injuries into three groups.

1. Minor injuries: Injuries that last for 1-7 days.

2. Medium injuries : 8-21 Injuries that last for 8-21 days.

3. Serious sports injuries: Injuries that prevent participation in sports longer than 21 days or cause permanent damage (Timpka et al. 2002).

Basketball players are injured by traumas in the form of excessive strain, impact and falling during training and competitions. Except for this type of trauma, the lack of physiological factors such as condition, skill, quickness, flexibility, concentration as well as the length and difficulty of sporting activity, facility, equipment and adverse seasonal conditions causes sports injuries. It is known that basketball players who play elite sports have high risk of injuries. It was observed that each basketball player was exposed to injuries that limit their performance at least once a year (Drakos et al. 2010).

Basketball players with team experience may encounter many psychological situations during, or before the competitions. Weather the experience character and the constructional characteristic of a team in athlete motivation is efficient is an attribute which should be studied in terms of the motivational climate. The environment of individuals' learning, skill development and assessment of activities is undertaken.

The sport researches related to success goals gather in two areas. First one concentrates on individual differences in goal orientation preferences. The studies in this area display the relations between goal orientation and cognitive and sentimental features (Duda, 1989). Second one is the studies on environmental factors. The relations of the goal orientation and the motivations of learning environment have been studied (Ames \& Archer, 1988). Those studies display that there is a strong bond between two areas and both together have effects, despite the fact that individual factors and case factors have examined respectively (Duda et al. 1992).

It is figured out that effective strategy uses, competitive preferences, positive attitudes in learning of team athletes observed much more in the mastery motivational climate (Ames \& Archer, 1988). Papaioannou denoted that perceived motivational climate is a factor in clarification of the athlete's goal orientation. Motivational climate competition level may consist elements like policy styles and important persons' effect. Two-factor theory has some explanations related to description and perception of team and individual success by athletes. According to this, athlete decides to success either by comparing his skills with other athletes, or comparing his current performance with his former performance. In both cases there is comparing standard. He sets his equivalents in the first one, his former performance standard in the second one as the comparison standard (Papaioannou, 1994).

Nicholls, Cheung ve Lauer dictates that the athletes make an effort to reach the some goals and after meeting the goals they acquire the success feeling. Also basketball players set some goals and in order to meet these goals, they go for several attitude orientation. These two goal orientations that we designate them as task and ego, are related with the individuals' determination of their skill level methods. It is indicated that the basketball player who has task oriented goals, concentrated on the areas like work hard, show proficiency in the task, skill development. It is expressed that the basketball players who have ego oriented goals make effort 
Bashan, I., \& Toros, T. (2018). The examination of motivational climate and goal orientation in basketball players-who did and did not experience a sports injury. Journal of Human Sciences, 15(4), 1854-1862. doi:10.14687/jhs.v15i4.5503

to prove their elegant skills. Individual success and beat his competitor in a game with lesser effort are important for the ego oriented player (Nicholls et al. 1989).

While the players who have task oriented goals believe to get success by good practice, cooperation with teammates and putting his best performance, the players who have ego oriented goals think to get success by proving their elegant skills and beating their competitors (Roberts, 1999). While a player in a basketball game turns two out of four shoots into score, in the next game the player who tries to make score three out of his four shoots is determined the task oriented goals. Also, the player who sets his goals ego oriented aims to make much more scores comparing to the opponent team player. Making better score than the competitor idea of the basketball players whose goals are ego oriented may cause various injuries.

\subsection{Aim of the research}

The sport injuries studies to date were looked over, it is seen that the relation between anxiety, personality and stress was emphasized. However no study seen emphasizing the relation between motivational climate and goal orientation. The relation of sport injuries with motivational climate and goal orientation would be studied in this article which is for the first time a study would be searching the relation of these variables with the injuries. Besides the relation of goal orientation and motivational climate would give a chance to the coaches to recognize, assess the players and enhance their perceptions. At the same time this article would provide valuable information in order to understand the sports psychology.

In this research it was aimed if there is a difference between mastery-performance climate and task-ego orientation variables of basketball players who did and did not experience a sports injury.

\section{Methodology}

\subsection{Research Model}

As the research model, a relational scan model was used consisting comparison among the variables and correlation type searches. The relational scan model is a method which is one of general scan model types aiming to depict a case as it was and to reveal the variation existence, degree and direction between two or more variables.

\subsection{Research Group}

This study group consists of 165 male basketball players who experienced mid-degree and serious sports injuries that are actively playing basketball in 18 years and older basketball teams and 142 male basketball players who did not experience any sports injury, or experienced a minor injury that are actively playing basketball in 18 years and older basketball teams, in total, 307 male basketball players. The average age of the athletes's is $24.52 \pm 04.21$. Participation to the study was done appropriately to the principles of voluntariness and privacy.

\subsection{Research Method}

The questionnaires were given to the basketball players before the training. The questionnaire information was explained to the players before the application. The research was authorized by the Mersin University Ethic Board ( February 02, 2018- 52793531-050.01.04).

\subsubsection{Data Collection Tools}

Following tools used in research group to collect data.

1-Perceived Motivational Climate in Sport Questionnaire (PMCSQ).

2-Task and Ego Orientation in Sport Questionnaire (TEOSQ) 
Bashan, I., \& Toros, T. (2018). The examination of motivational climate and goal orientation in basketball players-who did and did not experience a sports injury. Journal of Human Sciences, 15(4), 1854-1862. doi:10.14687/jhs.v15i4.5503

\subsubsection{Perceived Motivational Climate in Sport Questionnaire}

The questionnaire was developed by Walling et al. (1993). The perceived Motivational Climate in Sport Questionnaire is composed of 21 items, nine of which are performance and twelve of which are mastery climate. Questionnaire respondents make their participation in each item according to the five-point Likert assessment system. In the original study of the questionnaire, construct validity was made with both explanatory and confirmatory factor analysis support (Walling et al. 1993). The questionnaire is used to identify individual differences in the dimensions of mastery and performance climate in determining motivational climates. Adaptation of the questionnaire for Turkish athletes was made by Toros, (2001). In the adaptation study conducted by Toros, the internal consistency values calculated by cronbach alpha, which explains $51 \%$ of the general variance of the scale of the mastery and performance climate dimensions are 0.84 for mastery climate, 0.90 for performance and 0.66 for mastery climate of 3 -week test reliability, 0.74 for climate.

\subsubsection{Task and Ego Orientation in Sport Questionnaire}

The scale was developed by Duda \& Nicholss (1992). Task and Ego Orientation in Sport Questionnaire consisted of 13 questions, seven of which were related with task and six related with the ego orientation. Questionnaire respondents make their participation in each item according to the five-point Likert assessment system. The internal consistency of the scale in the original study was found 0.79 for the task orientation and 0.81 for the ego orientation and additionally the three-week test-retest reliability was found 0.68 for the task orientation and 0.75 for the ego orientation for Duda, (2001). The scale is used to determine the individual differences in task and ego orientation dimensions in determining target orientations. The adaptation of the scale for Turkish sportsmen was done by Toros (2001 \& 2004). In the adaptation study conducted by Toros (2001), the internal consistency values of two factors, task and ego orientation, calculated by cronbach and alpha, which explains $58 \%$ of the general variance, was found 0.87 for the task orientation, 0.85 for the ego orientation, and three weeks of test-retest reliability was found 0.65 for the task orientation, 0.72 for the ego orientation.

\subsection{Data Analysis}

First, descriptive statistics are used. Then Kolmogorov-Smirnov test was interpreted for normality to be able to determine whether the distribution is normal and due to group size is greater than 50. Looking at the tests of normality $\mathrm{p}$ values, since they were below 0.05 in all variables, it is determined that they are not displaying normal distribution. Furthermore, "the difference scores of the two affiliated sets of measures shows normal distribution" hypothesis, one of the affiliated t test's assumptions, has not been met. Mann-Whitney U-test, a nonparametric of the affiliated $T$ test, and Spearman correlation test, a nonparametric of the test, in order to determine the relationship between the scale sub-dimensions were used. Regarding the scales for internal consistency the Cronbach-alpha test was checked. In the study, 0.05 was used in the statistical process as the level of significance. SPSS 22 statistical package program was used in the analysis of the data obtained in the research. Reliability analyzes of scales used in research; a Cronbach Alpha reliability analysis was conducted for the scales used in the research (Task Orientation 0.84, Ego Orientation 0.85, Mastery Climate 0.80, Performance Climate 0.81).

\section{Findings}

The Mann Whitney U-test results of mastery climate average scores gotten thru the questionnaire of basketball players who did and did not experiencing sports injuries are given in Table 1. According to this it is not detected any significant difference among the mastery climate average scores of basketball players who did and did not experiencing sports injuries $(\mathrm{U}=8902$, $\mathrm{p}>0.05)$. 
Bashan, I., \& Toros, T. (2018). The examination of motivational climate and goal orientation in basketball players-who did and did not experience a sports injury. Journal of Human Sciences, 15(4), 1854-1862. doi:10.14687/jhs.v15i4.5503

\section{Table 1.}

The Mastery Climate of the Basketball Players who did and did not experience a sports injury

Group

\begin{tabular}{lcrrrr}
\hline & $\mathrm{n}$ & $\begin{array}{r}\text { Series } \\
\text { Average }\end{array}$ & $\begin{array}{r}\text { Series } \\
\text { Sum }\end{array}$ & $\mathrm{U}$ & $\mathrm{p}$ \\
\hline $\begin{array}{l}\text { Not experiencing } \\
\text { Sports Injury }\end{array}$ & 142 & 142.09 & 17800.00 & & \\
& & & & & \\
& & & & & \\
$\begin{array}{l}\text { Experiencing } \\
\text { Sports Injury }\end{array}$ & 165 & 137.67 & 20161.0000 & & \\
\hline
\end{tabular}

The Mann Whitney U-test results of performance climate average scores gotten thru the questionnaire of basketball players who did and did not experiencing sports injuries are given in Table 2. According to this it is not detected any significant difference among the performance climate average scores of basketball players who did and did not experiencing sports injuries $(\mathrm{U}=9121, \mathrm{p}>0.05)$.

\section{Table 2.}

Performance Climate of Basketball Players who did and did not Experience a Sports Injury

\begin{tabular}{lcrrrr}
\hline Group & \multicolumn{1}{c}{} & & \\
& $\mathrm{n}$ & $\begin{array}{r}\text { Series } \\
\text { Average }\end{array}$ & $\begin{array}{r}\text { Series } \\
\text { Sum }\end{array}$ & $\mathrm{U}$ & $\mathrm{p}$ \\
\hline $\begin{array}{l}\text { Not experiencing } \\
\text { Sports Injury }\end{array}$ & 142 & 142.01 & 17845.00 & & \\
& & & & & \\
& & & & & \\
Experiencing & 165 & 137.97 & 20311.00 & & \\
Sports Injury & & & & & \\
\hline
\end{tabular}

The Mann Whitney U-test results of task orientation average scores gotten thru the questionnaire of basketball players who did and did not experiencing sports injuries are given in Table 3. According to this it is not detected any significant difference among the task orientation average scores of basketball players who did and did not experiencing sports injuries ( $U=9432$, $\mathrm{p}>0.05)$. 
Bashan, I., \& Toros, T. (2018). The examination of motivational climate and goal orientation in basketball players-who did and did not experience a sports injury. Journal of Human Sciences, 15(4), 1854-1862. doi:10.14687/jhs.v15i4.5503

\section{Table 3.}

Task Orientation of Basketball Players who did and did not Experience a Sports Injury

Group

\begin{tabular}{|c|c|c|c|c|c|}
\hline & $\mathrm{n}$ & $\begin{array}{r}\text { Series } \\
\text { Average }\end{array}$ & $\begin{array}{r}\text { Series } \\
\text { Sum }\end{array}$ & $\mathrm{U}$ & $\mathrm{p}$ \\
\hline \multirow[t]{2}{*}{$\begin{array}{l}\text { Not experienc } \\
\text { Sports Injury }\end{array}$} & 142 & 136.91 & 17623.00 & \multirow{3}{*}{9432.00} & \multirow{3}{*}{0.970} \\
\hline & & & & & \\
\hline $\begin{array}{l}\text { Experiencing } \\
\text { Sports Injury }\end{array}$ & 165 & 137.02 & 20811.00 & & \\
\hline
\end{tabular}

The Mann Whitney U-test results of ego orientation average scores gotten thru the questionnaire of basketball players who did and did not experiencing sports injuries are given in Table 4. According to this it is not detected any significant difference among the ego orientation average scores of basketball players who did and did not experiencing sports injuries $(\mathrm{U}=8874$, $\mathrm{p}>0.05)$.

Table 4.

Ego Orientation of Basketball Players who did and did not Experience a Sports Injury

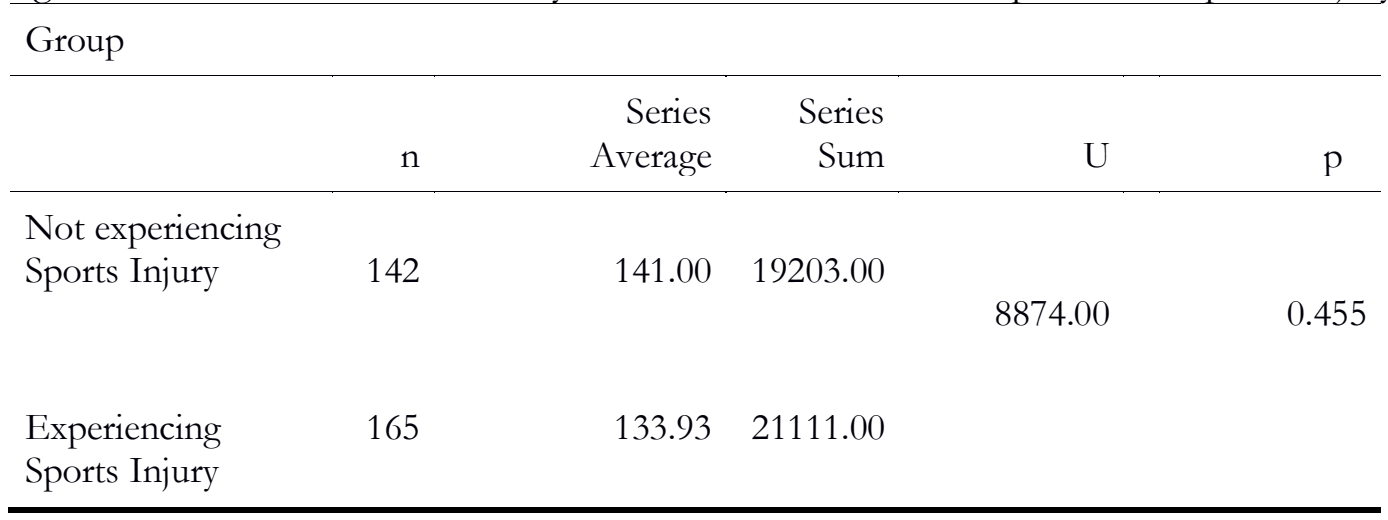

There is a positive significant relation between Ego Orientation and Mastery Climate $\left(\mathrm{r}=0.341^{* *}\right)$, Ego Orientation and Performance Climate $\left(\mathrm{r}=0.618^{* *}\right)($ Table 5) 
Bashan, I., \& Toros, T. (2018). The examination of motivational climate and goal orientation in basketball players-who did and did not experience a sports injury. Journal of Human Sciences, 15(4), 1854-1862. doi:10.14687/jhs.v15i4.5503

\section{Table 5.}

Spearman Correlation Test between Motivational Climate and Goal Orientation of Basketball Players who did and did not Experience a Sports Injury

\begin{tabular}{|l|l|l|}
\hline $\begin{array}{l}\text { Spearman Correlation } \\
n=307\end{array}$ & Mastery Climate & Performance Climate \\
\hline Task Orientation & $\begin{array}{l}0.341(* *) \\
0.000\end{array}$ & $\begin{array}{l}0.099 \\
0.212\end{array}$ \\
\hline Ego Orientation & $\begin{array}{l}0.045 \\
0.609\end{array}$ & $\begin{array}{l}0.618(* *) \\
0.000\end{array}$ \\
\hline
\end{tabular}

\section{Discussion and Conclusion}

In this study, it was aimed to determine whether there is a difference between the masteryperformance climate and the task-ego orientation variables of basketball players who did and did not experience sports injuries.

In basketball, motivation and athletic support of teammates is important. For this reason, teams can work with the team in the psychological support program. In basketball teams whose coaches create a mastery climate, success comes quicker. But at the same time as the success comes, sports injuries in the team begins to emerge. The feeling of loss of identity that injured players may encounter can be a reason for not having significant difference in the basketball players experiencing sports injury who have mastery climate. Along with the mastery climate created by the coach, basketball players who have devoted themselves to the sports can experience a sense of identity loss. Because, when a player is injured, the person whose role of the sport has been taken away may experience psychological depression. Such players may need to be motivated by the coach, family and the environment by creating a team climate. The results of Petitpas \& Danish (1995) study support the findings of the research conducted.

Self improvement of basketball players whose performans climate is high can be lover than the basketball players whose mastery climate is lower. The reason why there is no significant difference in our research may be that the athletes have feelings of loneliness and introversion after the injury. The injured athlete may have influenced the performance climate, thinking that he lost support of the community and supporters because he left sports for a while after the injury. Many sports psychologists believe that in these situations, the athlete will be able to recover more quickly from psychological situation, if they are in the group with simple tasks in the same environment with the team, instead of being removed from the team. However, watching the training by injured athletes training is often not adopted by coaches due to the view that will have a negative impact on the athletes. Having said that injured but safe athletes, keep accepting themselves and think positively even if some anticipations do not materialize. In some studies, it has been pleaded that negative thinking athletes meet more frequently with injuries (Bergandi, 1985; Tracey 2010).

For many athletes the injury and treatment process can be very stressful. It can also cause depression in elite athletes with high self-confidence. The degree of injury, how it has happened, his life, his reaction and the people behind him are affect the treatment. Therefore, the response of the athletes to the injury will vary from one to another. Due to the basketball players with task-oriented goals concentrate more on self-improvement, effort and being better, there may not be a significant difference in this study. Mankad et al. (2009) reported that in their research 
Bashan, I., \& Toros, T. (2018). The examination of motivational climate and goal orientation in basketball players-who did and did not experience a sports injury. Journal of Human Sciences, 15(4), 1854-1862. doi:10.14687/jhs.v15i4.5503

examining the psychological characteristics of injured athletes, the sample group experienced significant psychological conditions such as deprivation of athlete identity, no further play, and rehabilitation in the long term healing process; they tend to stay away from the social environment, from the team and the training environment during the treatment process. For this reason, studies on psychological characteristics before and after disability rather than on rehabilitation, will enrich the literature in this area.

When many studies are examined, the results of the tests on injured athletes have consistently obtained the same psychological findings so that the significance of this matter has emerged. The reason why there is no meaningful difference in ego orientation in our research is that basketball players may be involved in behaviors such as making better from their opponents or teammates, showing themselves and overcoming the ones they see as competitors. Levy et al. (2008) studied the impact and relationship of an integrated psychosocial program in their studies of psychology of sports injuries. In this study, it was found that there is a significant relationship between self-efficacy and self-motivation, adherence to clinical program, adherence to home schedule, intention, learning orientation and attendance.

When the findings of this study are examined; it can be done to cover different branches. In addition, more complex skills on basketball can be chosen. However, the psychological conditions seen during training can be examined in more detail for the risk of injuries to athletes. Also gender differences can be examined in the further researches. As a result, it is thought that discussing the interaction of different dimensions of sport psychology, new horizons will be opened in sports science area in the future.

\section{References}

Ames, C., \& Archer, J. (1988). Achievement goals in the classroom: Students' learning strategies and motivation processes. Journal of Educational Psychology, 80(3), 260-267.

Bergand1, T.A. (1985). Psyhogical Variables Relating to the Incidence of Athletic Injury: A Review of the Literature. International Journal of Sport Psychology, 16, 141- 149.

Drakos, M.C., Domb, B., Starkey, C., Callahan, L., Allen, A.A. (2010) Injury in the National Basketball Association A 17-Year Overview. Sports Health, 2(4), 284-290.

Duda, J.L. (1989). The relationship between task and ego orientation and the perceived purpose of sport among male and female high school athletes. Journal of Sport and Exercise Psychology, $11,318-335$.

Duda, J.L., Fox, K.R., Biddle, S.J., Armstrong, N. (1992). Children's achievement goals and beliefs about success in sport. British Journal of Educational Psychology, 62(3), 313-323.

Duda, J.L., Nicholls, J.G. (1992). Dimensions of achievement motivation in schoolwork and sport. Journal of Educational Psychology, 84(3), 290-299.

Duda, J.L. (2001). Achievement goal research in sport: Pushing the boundaries and clarifying some misunderstandings. In. Roberts GC, (Ed.), Advances in motivation in sport and exercise (pp. 129-182). IL, US: Human Kinetics Books, Champaigne.

Levy, A.R., Polman, R.C.J., Claugh P.J. (2008). Adherence to Sport Injury Rehabilitation Programs: An Integrated Psycho- Social Approach. Scandinavian Journal of Medicine \& Science in Sports, 18, 798- 809.

Mankad, A., Gordon, S., Wallman, K. (2009). Perceptions of Emotional Climate Among Injured Athletes. Journal of Clinical Sport Psychology, 3, 1- 14.

Nicholls, J.G., Cheung, P.C., Lauer, J., Patashnick, M. (1989). Individual differences in academic motivation: Perceived ability, goals, beliefs, and values. Learning and Individual Differences, 1(1), 63-84.

Papaioannou, A. (1994). Development of a questionnaire to measure achievement orientations in physical education. Research Quarterly for Exercise and Sport, 65(1), 11-20. 
Bashan, I., \& Toros, T. (2018). The examination of motivational climate and goal orientation in basketball players-who did and did not experience a sports injury. Journal of Human Sciences, 15(4), 1854-1862. doi: $10.14687 /$ ihs.v15i4.5503

Petitpas, A. \& Danish S.J. (1995). Caring for Injured Atbletes. In. Murphy, S.M. (Ed.), Sport Psychology Interventions (pp. 253-306). Champain III: Human Kinetics.

Roberts, R.E., Phinney, J.S., Masse, L.C., Chen, Y.R., Roberts, C.R., Romero, A. (1992). The structure of ethnic identity of young adolescents from diverse ethnocultural groups. Journal of Early Adolescence, 19(3), 301-322.

Timpka, T., Risto, O., Lindqvist, K. (2002). Injuries in competitive youth bandy: an epidemiological study of a league season. Medicine and Science in Sports and Exercise, 34(6), 993-997.

Timpka, T., Jacobsson, J., Bickenbach, J., Finch, C.F., Ekberg, J., Nordenfelt, L. (2014). What is a sports injury? Sports Medicine, 44(4), 423-8.

Toros T. (2001). The Affects of Goal Orientation, Motivational Climate and the Degree Of Originality of Targets to Life Satisfaction. Unpublished doctoral dissertation. Mersin, Turkey; Mersin University.

Toros T. (2004). Reliability and validity of" Task and Ego Orientation in Sport QuestionnaireTEOSQ-" for Turkish athletes. Hacettepe Journal of Sport Sciences, 15(3), 155-166.

Tracey, J. (2010). The Emotional Response to the Injury and Rehabilitation Process. Journal of Applied Sport Psychology, 279-293.

Walling, M.D., Duda, J.L., Chi, L. (1993). The perceived motivational climate in sport questionnaire: Construct and predictive validity. Journal of Sport and Exercise Psychology, 15(2), 172-183. 